\title{
Commentary: Emotion effects on implicit and explicit musical memory in normal aging
}

\author{
Nicola Mammarella* \\ Psychological Sciences, Health and Territory, Università degli Studi "G. d'Annunzio" Chieti - Pescara, Chieti, Italy
}

Keywords: implicit memory, emotion, aging, positivity bias, music cognition

\section{A commentary on}

Emotion effects on implicit and explicit musical memory in normal aging by Narme, P., Peretz, I., Strub, M.-L., and Ergis, A.-M. (2016). Psychol. Aging 31, 902-913. doi: $10.1037 /$ pag0000116

Implicit emotional memory refers to unconscious retrieval of past emotional experiences (e.g., Graf and Schacter, 1985). The study by Narme et al. (2016) is one of the first to examine age-related changes in implicit emotional memory using unfamiliar emotional melodies that varied in terms of valence (positive: peaceful and happy; negative: sad and fearful) and arousal (high or low). Implicit memory was assessed with a preference task in which participants rated their liking of previously studied or new melodies. In particular, 113 participants were involved, 60 younger adults $(58.3 \%$

OPEN ACCESS

Edited by: Alessio Avenanti, Università di Bologna, Italy

Reviewed by:

Giorgio Sandrini,

University of Pavia, Italy

Gunter Kreutz,

University of Oldenburg, Germany

*Correspondence: Nicola Mammarella n.mammarella@unich.it

Specialty section: This article was submitted to

Emotion Science,

a section of the journal

Frontiers in Psychology

Received: 19 September 2017 Accepted: 05 December 2017 Published: 14 December 2017

Citation:

Mammarella N (2017) Commentary: Emotion effects on implicit and explicit musical memory in normal aging.

Front. Psychol. 8:2208

doi: 10.3389/fpsyg.2017.02208 women, mean age 23.6) and 53 older adults (68\% women, mean age 75.3 ). These two groups of participants first heard a list of musical excerpts and then they had to indicate whether each musical piece had a fast or slow tempo. Half of melodies were played twice and the other half six times. Subsequently, participants were asked to rate how much they liked each melody using a 10-point scale (from $1=I$ do not like it at all to $10=I$ like it a lot) for old and new excerpts.

Although there was a slight decrease in implicit memory, results show that exposure effects, that is, higher liking ratings for old melodies compared with new ones, occurred in both groups. Most importantly, the authors found no particular aging effects on emotional implicit memory for music, for example, in terms of the classical age-related positivity effect (e.g., Mather, 2012). In fact, there were no stronger exposure effects for positive melodies.

Given the general preservation of implicit memory (e.g., Jelicic, 1995; LaBar et al., 2005; Ward et al., 2013) coupled with the well-established positivity effect in the aging mind (e.g., Mather, 2012; Di Domenico et al., 2015), these data are intriguing. The rationale being that studying emotional memory-music interaction in aging is complex due to differences between emotion processing, in general, and the emotional processing of music, in particular.

From the emotion processing literature' point of view, one viable account for explaining the absence of positivity effects may be linked to the level of stimulus familiarity at test. This may be particularly true in the presence of musical excerpts and lead to a consequent modulation of valence effects. There are studies, in fact, showing how positive valence is typically linked to processing fluency and feelings of familiarity such as the more fluently people process an event, the more positive is their response (e.g., Winkielman and Cacioppo, 2001; Berridge and Winkielman, 2003). Therefore, if participants assign a certain level of familiarity to the target at test, they may tend to react in a positive manner, even in the presence of negative events. Consequently, results should be taken with caution. The general findings that participants liked the excerpts they heard six times more than those they heard twice and that no valence effects occurred especially with high arousing stimuli in the older adults' group may point to this direction. 
Moreover, the authors stated that the absence of a positivity effect in implicit memory in older adults suggests that the positivity effect stems from top-down processes. This conclusion did not take into account studies (e.g., Hess et al., 2004) showing that older adults' memory performance could be unconsciously influenced by the activation of negative and positive aging stereotypes. In particular, older adults' performance was significantly lower in the negative priming condition than in the positive. In addition, age differences were significantly reduced following the positive prime.

Another relevant aspect of the study is the potential for explicit contamination. As suggested by Mulligan (2011), when given an implicit memory test, participants may become aware of the relationship between study and test and consequently engage in intentional retrieval. The authors did not use, for instance, any post-test questionnaire to determine if participants were aware of the connection between the study and test phases of the experiment (the authors themselves acknowledged this as a limitation).

Finally, another aspect that need further consideration refers to mood-congruent effects in implicit memory, that is the finding that emotional information congruent with current mood is more likely to be recalled than information incongruent with current mood. For example, Gaddy and Ingram (2014) found that depressive groups exhibited preferential implicit recall of negative information and non-depressed groups exhibited preferential implicit recall of positive information. Although older adults were screened for depression, it is possible that musical excerpts themselves acted as a mood induction technique and later influenced implicit emotional memory.

\section{REFERENCES}

Berridge, K. C., and Winkielman, P. (2003). What is an unconscious emotion? (The case for unconscious "liking"). Cogn. Emot. 17, 181-211. doi: 10.1080/02699930302289

Di Domenico, A., Palumbo, R., Mammarella, N., and Fairfield, B. (2015). Aging and emotional expression: is there a positivity bias during dynamic emotion recognition? Front. Psychol. 6:1130. doi: 10.3389/fpsyg.2015. 01130

Fairfield, B., Mammarella, N., Di Domenico, A., and Palumbo, R. (2015). Running with emotion: when affective content hampers working memory performance. Int. J. Psychol. 50, 161-164. doi: 10.1002/ijop.12101

Gaddy, M. A., and Ingram, R. E. (2014). A meta-analytic review of moodcongruent implicit memory in depressed mood. Clin. Psychol. Rev. 34, 402-416. doi: 10.1016/j.cpr.2014.06.001

Graf, P., and Schacter, D. L. (1985). Implicit and explicit memory for new associations in normal and amnesic subjects. J. Exp. Psychol. Learn. Mem.Cogn. $11,501-518$

Hess, T. M., Hinson, J. T., and Statham, J. A. (2004). Explicit and implicit stereotype activation effects on memory: do age and awareness moderate the impact of priming? Psychol Aging, 19, 495-505. doi: 10.1037/0882-7974.19.3.495

Jelicic, M. (1995). Aging and performance on implicit memory tasks: a brief review. Int. J. Neurosci. 82, 155-161.

LaBar, K. S., Torpey, D. C., Cook, C. A., Johnson, S. R., Warren, L. H., et al. (2005). Emotional enhancement of perceptual priming is preserved in aging and early-stage Alzheimer's disease. Neuropsychologia 43, 1824-1837. doi: 10.1016/j.neuropsychologia.2005.01.018

Mather, M. (2012). The emotion paradox in the aging brain. Ann. N. Y. Acad. Sci. 1251, 33-49. doi: 10.1111/j.1749-6632.2012.06471.x
From the emotional processing of music's perspective, one can argue that the distinction between positive and negative valence typically found in emotion research may not apply to a full extent to music. In fact, music processing relies on a series of cognitive skills (e.g., decoding of pitch, rhythm, timbre, and processing of sequential elements that may convey emotions) and a series of neural networks (e.g., amygdala, nucleus accumbes, posterior cingulate cortex) that show age-related differences (from newborns to older adults, e.g., Perani et al., 2010) and are strongly modulated by lifelong experiences (e.g., Spada et al., 2014). Consequently mental representations of an auditory scene and the corresponding emotional meaning may reflect the interaction between top-down and bottom-up processes.

In sum, while Narme et al.'s data are some of the first to focus on implicit emotional memory in aging, it has to be acknowledged that the study of emotional memory-music interaction is complex. For example, a familiarity and fluencybased interpretation of the interaction between implicit memory and emotion cannot be ignored. In addition, controlling for explicit contamination (e.g., Fairfield et al., 2015) is highly relevant for directing future research in this new area, especially in the aging mind. However, researchers in emotion-memory interaction must be aware that emotion processing findings and explanations cannot be easily applied to the context of music processing.

\section{AUTHOR CONTRIBUTIONS}

The author confirms being the sole contributor of this work and approved it for publication.

Mulligan, N. W. (2011). Conceptual implicit memory and environmental context. Conscious Cogn. 20, 737-744. doi: 10.1016/j.concog.2010.11.008

Narme, P., Peretz, I., Strub, M.-L., and Ergis, A.-M. (2016). Emotion effects on implicit and explicit musical memory in normal aging. Psychol. Aging 31, 902-913. doi: 10.1037/pag0000116

Perani, D., Saccuman, M. C., Scifo, P., Spada, D., Andreolli, G., Rovelli, R., et al. (2010). Functional specializations for music processing in the human newborn brain. Proc. Natl. Acad. Sci. U.S.A. 107, 4758-4763. doi: 10.1073/pnas.0909074107

Spada, D., Verga, L., Iadanza, A., Tettamanti, M., and Perani, D. (2014). The auditory scene: an fMRI study on melody and accompaniment in professional pianists. Neuroimage 102(Pt 2), 764-775. doi: 10.1016/j.neuroimage.2014.08.036

Ward, E. V., Berry, C. J., and Shanks, D. R. (2013). An effect of age on implicit memory that is not due to explicit contamination: implications for single and multiple-systems theories. Psychol. Aging 28, 429-442. doi: 10.1037/a0031888

Winkielman, P., and Cacioppo, J. T. (2001). Mind at ease puts a smile on the face: psychophysiological evidence that processing facilitation elicits positive affect. J. Pers. Soc. Psychol. 81, 989-1000. doi: 10.1037/0022-3514.81.6.989

Conflict of Interest Statement: The author declares that the research was conducted in the absence of any commercial or financial relationships that could be construed as a potential conflict of interest.

Copyright (C) 2017 Mammarella. This is an open-access article distributed under the terms of the Creative Commons Attribution License (CC BY). The use, distribution or reproduction in other forums is permitted, provided the original author(s) or licensor are credited and that the original publication in this journal is cited, in accordance with accepted academic practice. No use, distribution or reproduction is permitted which does not comply with these terms. 